\section{Questión}

Periodismo / Comunicación ISSN 1669-6581
- Av. $44 \mathrm{~N}^{\circ} 676,1^{\circ}$ piso

CP 1900 - La Plata - Argentina

www.perio.unlp.edu.ar/question

La Cultura en Cuarentena

Emiliano Rimoldi

DOI: https://doi.org/10.24215/16696581e303

\title{
La Cultura en Cuarentena
}

\section{Culture in Quarantine}

Hay dos certezas que parecieran ser puntos de partida para cualquier debate acerca de la pandemia de COVID-19 y sus implicancias sociales y económicas. En primer lugar, se reconoce que estamos transcurriendo un momento bisagra en la historia mundial. De aquí pueden desprenderse las posturas que plantean el triunfo de tal o cual potencia económica, el advenimiento de una extraña nueva superación comunista o, quizás más sensatamente, la transición hacia un nuevo modelo de acumulación capitalista. Pero hay consenso de la magnitud del momento histórico que estamos viviendo. Consecuentemente con este punto, se nos impone la necesidad de mutar para esta nueva gran cosa hacia la que nos encaminamos. Nadie sabe exactamente cómo hacerlo o qué rumbo tomar, pero la voluntad sobra. La astucia está en no apresurarse en intentos que, por ausencia de consensos entre los actores involucrados en cada ámbito del debate, nos hagan dar pasos en falso o -lo que es aún peornos hagan caminar por rumbos diferentes.

El otro punto de partida de los debates actuales es, más bien, una sensación. Esa sensación de estar frente a un gran manto de sombra que avanza con una desesperante lentitud sobre la humanidad. Una sombra que comienza con la pandemia, sigue con el derrumbe económico y 
termina quién sabe dónde. Se puede debatir la proyección real del avance del virus o la eficacia de las medidas de distanciamiento pero nadie duda de que viene para largo. En Argentina, incluso, con una inusitada rapidez y una inteligente gestión de recursos en el marco de la crisis, el gobierno impulsó las medidas de distanciamiento cuando apenas había 56 casos confirmados. A partir de allí se comenzó un amplio operativo de recuperación y readecuación de espacios con el fin de poner en pie el derruido sistema de salud que dejó el experimento neoliberal de los CEOs que gobernaron en el período 2015/2019. En este sentido, la lentitud de este enemigo desconocido es para nuestro país una ventaja. Nos permite equiparnos, reconstruir, remodelar y sumar acciones para esperar un posible pico de contagios.

Sin embargo este tiempo a algunos sectores se nos hace eterno y desahuciante. El Aislamiento Social, Preventivo y Obligatorio decretado desde el 20 de marzo llevó a las industrias culturales al pico de una prolongada crisis. Se trata del punto más alto de una situación de emergencia que se inició en 2015, con el proceso de transferencia de recursos (económicos, políticos y tecnológicos) hacia los grupos concentrados de poder financiero, jurídico y comunicacional. A la crisis económica se sumaron, particularmente en nuestra región, oleadas de clausuras y persecución a varios espacios culturales. Éstos conforman el epicentro de producción, circulación y formación de gran parte del contenido que nutre la cultura de nuestra ciudad. La combinación de limitaciones económicas y clausuras aplanó la curva de crecimiento -para usar un término de moda- de un incipiente pero firme proceso de consolidación que se estaba viviendo en las industrias culturales de La Plata hacia fines de 2015 y principios de 2016.

Es decir que las industrias culturales de nuestra región ya estaban en crisis, pero funcionando. El aislamiento obligó a cerrar las puertas de los centros culturales, cancelar recitales, muestras, obras, talleres, clases y todas las actividades que sustentan estas industrias. Pueden pensarse a los espacios culturales alternativos como entidades vivas que están privadas de su fuente de nutrición: el encuentro. Viven por, para y de los encuentros. Son su razón de ser. En los encuentros se generan las nuevas formas de relaciones sociales, los nuevos lazos a partir de los cuales se proponen otros tipos de mundos posibles. Estos lazos son el medio de circulación de los recursos económicos, cognitivos, estéticos e incluso energéticos que garantizan la sostenibilidad de los Espacios y los puestos de trabajo que allí se generan.

El aislamiento, entonces, erige como el pico más alto de la crisis al impedir el funcionamiento esencial de los espacios culturales, así como de los medios principales de sustento de estas 
industrias. Pero, además, precipita una serie de debates que marcan puntos interesantes a futuro.

Las ideas que aquí se juntan, tienen el objetivo de recopilar y sistematizar las prácticas y debates que vienen surgiendo en el marco de esta crisis. No hay lugar para arriesgar certezas a futuro, ya que todo está apresuradamente en pleno suceso y constante transformación. La intención de este escrito, producido desde el mismo ojo del huracán, se basa en la tarea de intentar abstraerse para juntar los datos que se puedan de esta tormenta que todavía está sucediendo. La idea es sintetizar los sucesos colectivos, los debates, las acciones y experiencias que nos dejarán aprendizajes, reflexiones y preguntas útiles para reinventarnos en este largo proceso de cambios que nos espera.

A partir de todas estas premisas, es posible identificar cinco ejes en los que se centra el debate de quienes trabajamos en el marco de las industrias culturales en la ciudad de La Plata:

\section{Lo económico}

El debate urgente. No sólo por la dependencia del encuentro como medio de subsistencia, sino porque el aislamiento encontró a la mayoría de los proyectos culturales desprovistos de estructuras para sostenerse económicamente por fuera de lo habitual. No había una base edificada para la producción, distribución y, sobre todo, monetización de las prácticas digitales. Poco se había ahondado en mecanismos contemporáneos de intercambio digital. Por supuesto que existen excepciones, como pueden ser, por ejemplo, los proyectos musicales de mayor alcance que tengan la posibilidad de cobrar por sus reproducciones en plataformas de streaming. Sin embargo, no es el caso de la gran mayoría de proyectos culturales de nuestra ciudad. Quizás porque no hacía falta, ya que el modo en que se reproducian los consumos culturales hasta ahora permitía a artistas, talleristas, productores y espacios sostener sus proyectos culturales a partir de lo que recaudaban en los eventos presenciales.

Entonces comenzaron a surgir nuevos modos de sostenimiento económico ante la emergencia: clases virtuales, donaciones, bonos contribución, rifas, delivery de productos, etc. Los actores que primero lanzaron sus proyectos de financiamiento independiente fueron los espacios culturales alternativos y algunos rubros de talleristas. Los primeros, por la complejidad de sostener económicamente un lugar con estas características: pago de alquileres, servicios básicos (luz, agua, gas), impuestos, servicios complementarios (como por ejemplo la conexión 
a internet) y requisitos que son condición para obtener la habilitación municipal (ambulancia y seguro de responsabilidad civil), entre otros gastos. En los casos que cuentan con la habilitación municipal definitiva (un pequeño porcentaje del total, cuya mayoría cuenta con habilitación provisoria o incluso no tiene habilitación) arrastran también un problema previo que tiene que ver con el cobro del subsidio municipal establecido en la ordenanza $N^{\circ} 11301$. Ante esta situación, las acciones alternativas fueron las primeras medidas, que mutaron con el correr de los días y las experiencias, para sostener los Espacios Culturales.

En el caso de Ixs talleristas, sólo continuaron Ixs que pueden realizar sus talleres en modalidad virtual. Esta distinción se vale, en primer lugar, de que no todos los talleres artísticos cumplen las condiciones para realizarse de forma no presencial; y, en segundo lugar, de lo que implica realizar esto en términos de accesibilidad tecnológica.

En el caso de Ixs artistas la cuestión económica es más compleja, ya que las condiciones para monetizar la realización, reproducción y venta de obras artísticas ya eran bastante deficientes antes del aislamiento. La apuesta entonces fue fortalecer la presencia en las redes sociales, lo que en el mejor de los casos repercute en plataformas de streaming con mayores reproducciones de música o videos, venta virtual de productos, obras y merchandising o la apuesta -quizás en menor medida- a métodos tradicionales de valorización de las obras.

\section{Lo laboral}

Se calculan que, por cada espectáculo suspendido de menos de 100 personas (tal era el caso de gran parte de los eventos que cada fin de semana movían la agenda cultural de nuestra región), quedan desempleadas entre 10 y 20 personas. Los números, por supuesto, se agrandan cuando se ponen en conjunto con otros datos: existen más de 100 espacios culturales alternativos en funcionamiento, grandes producciones y festivales organizados por colectivos independientes, una variedad de bares, salas de concierto, teatros, galerías, salas de exposición, una agenda bastante movida de artistas mainstream que visitan la ciudad de La Plata cada fin de semana, y la lista sigue. En cada una de las actividades de la nutrida agenda cultural platense están Ixs artistas, pero también productorxs, managers, taquillerxs, recepcionistas, sonidistas, iluminadorxs, VJs, asistentes de escenario, escenógrafxs, personal de seguridad, vestuaristas, maquilladorxs, mozxs, personal de limpieza, y la lista siempre se queda corta. 
La derivada directa de los problemas económicos generados por el aislamiento y el cierre de los espacios culturales es la pérdida de fuentes laborales. Pero, además, aflora una de las problemáticas que afecta a la gran mayoría de los proyectos culturales de la región desde hace varios años: la informalidad de esos puestos de trabajo. Las industrias culturales están compuestas por un número variado de actorxs, en un tejido que involucra redes de cuentapropistas. En el mejor de los casos estos trabajadorxs facturan el trabajo que realizan y eso quizás les permita acceder a algunos beneficios, pero son muchxs Ixs que no han accedido a ningún grado de formalidad.

$\mathrm{Si}$ tomamos el caso de las industrias y espacios culturales alternativos, el grado de formalización todavía es muy bajo. Si bien éstos son reconocidos como sector y tienen varios años de desarrollo, todavía se encuentran en una etapa de formalización. Los factores que llevan a esta problemática seguramente varían según el caso puntual, pero podemos destacar algunos que constituyen un marco en común: a) muchos espacios culturales todavía no completaron los requisitos para la habilitación definitiva; b) la Ordenanza $\mathrm{N}^{\circ} 11301$, que rige desde 2015, no termina de consolidarse a partir de una aplicación definitiva de todos sus instrumentos; c) la crisis que se acarrea desde hace unos años frenó y dificultó el proceso de consolidación de los espacios culturales; d) muchos espacios cerraron sus puertas a raíz de esa crisis y otros tantos abrieron como pequeños emprendimientos de trabajadorxs desocupadxs que buscaban "parar la olla" y lograron recaudar lo mínimo para sostenerse.

La informalidad laboral, entonces, es un problema que arrastran desde hace varios años las industrias culturales (como muchos otros sectores económicos de nuestro país), pero que nos estalla en la cara a partir del aislamiento, convirtiéndose en uno de los puntos centrales del debate cultural en estos tiempos.

\section{Lo tecnológico}

El decreto del ASPO nos llevó a un vuelco compulsivo hacia dispositivos virtuales de comunicación, producción y difusión. Las redes sociales estallaron de nuevos contenidos y pareciera haber un incremento del público en esas plataformas. Sin embargo, a Ixs actorxs culturales se nos vino encima una abrupta oleada tecnológica. La situación presenta dos caras: por un lado, las plataformas en donde se está poniendo en juego todo el proceso de socialización en la actualidad ayudan a democratizar el acceso a la difusión de los proyectos 
culturales. Por otro lado, transforman los modos de producción e imponen nuevos límites al entramado de comunicación y distribución que no siempre nos quedan cómodos. Además, hay que tener en cuenta que como base de este debate está la capacidad económica de acceso a los equipamientos tecnológicos y a los recursos cognitivos para lograr producciones de calidad con las tecnologías disponibles en el aislamiento. Las posibilidades de producción van a estar limitadas, entonces, al capital tecnológico que posea cada proyecto cultural.

En ese sentido, las dos caras de la moneda están fuertemente presentes durante todo este proceso. Se ven colaboraciones de artistas a distancia, producciones caseras que logran buen nivel de calidad, nuevas redes de actores que antes no producían juntxs, numerosos desafíos virtuales, un sinfín de transmisiones en vivo y una explosión de creatividad para utilizar las redes a favor de Ixs artistas. En muchos casos ha servido para ensanchar el público de las redes sociales, que ya eran el principal medio de difusión de cualquier proyecto cultural independiente.

Sin embargo, la primera traba aparece a la hora de monetizar este trabajo. Como analizamos anteriormente, todavía no contamos con estructuras de economía digital firmes y socializadas. Además, se está observando una saturación de información en la primera etapa de este proceso y muchxs productorxs, gestorxs y artistas ven pocas posibilidades de sostenerlo en el tiempo. Un artista o colectivo artístico puede realizar varias presentaciones por mes, pero ¿cuántos eventos virtuales pagos en el marco de una saturación informativa se harían sostenibles?. Por el momento no parece haber alternativas, aunque mucho se está debatiendo al respecto ya que todxs Ixs actores de la cultura coinciden en que esta situación va a ser larga y que los espacios culturales serán los últimos en abrir. En este punto, el debate se torna más complejo: ¿qué hacemos cuando pase el aislamiento? ¿si nos quedan algunos meses en el año para producir, todos los proyectos culturales saldremos al mismo tiempo? ¿habrá público para tanta oferta? ¿cómo se reconfigurarán los contenidos a partir de los límites que imponen las plataformas digitales? ¿el sistema de valores de las redes sociales (los puntos por popularidad que significan los likes, las reproducciones, etc), se tornará determinante? ¿qué capacidad tendremos para operar sobre estas limitaciones y hacerlas jugar a nuestro favor?. Por supuesto que cualquier respuesta es arriesgada, pero poner esas preguntas sobre la mesa ayuda a pensar de qué forma las industrias culturales deben mutar, haciendo necesariamente uso de las tecnologías, para subsistir. 
El caso de los espacios culturales es particular. Éstos están enlazados al lugar físico que ocupan en la ciudad y a su relación con la comunidad. El desplazamiento hacia nuevos territorios digitales limita su potencial para funcionar como nodos que articulan el entramado de producción, distribución y formación de los proyectos culturales. Con sus puertas cerradas, todos los eslabones de las industrias culturales se ven afectados. Ahora son las plataformas digitales las que imponen las fronteras de lo que se puede hacer, cómo se puede hacer y en cuánto tiempo.

\section{Lo institucional}

El plano institucional es otro de los principales ejes de debate cultural en la ciudad de La Plata. La relación con el Estado ha sido un tema central para las industrias culturales en los últimos años. Luego de largos procesos de lucha por el reconocimiento del sector, en 2015 se logró conseguir la Ordenanza Municipal №11301 que otorga derechos y habilita las actividades de los espacios culturales alternativos. Este fue un hito fundamental en un proceso de consolidación de la cultura platense, pero los años que siguieron frenaron ese proceso de avance colectivo. La transferencia de recursos hacia el poder concentrado que comandó el gobierno de Cambiemos golpeó duramente a las industrias culturales. Éstas se vieron afectadas por la baja generalizada de las posibilidades de consumo de gran parte de la población, el aumento de las tarifas, la inflación, la devaluación de la moneda nacional, el aumento de los alquileres, etc.

A la crisis económica, en el territorio municipal se sumó un foco de conflicto con las clausuras a espacios culturales y el incumplimiento de varios puntos establecidos en la Ordenanza No11301.

En este sentido, la relación con las instituciones estatales venía deteriorada para cuando llegó la pandemia a nuestro país. Los pocos meses del nuevo gobierno no llegaron a recomponer estas relaciones más allá de lo declamativo, sin embargo actualmente la acción estatal es clave para superar esta crisis.

El Estado nacional tuvo rápidas respuestas para las entidades legalmente reconocidas y, más tarde, impulsó subsidios y créditos para el resto de las organizaciones y espacios culturales. Se destacan las iniciativas del Fondo Desarrollar, el programa Puntos de Cultura y el Plan Podestá para potenciar el Teatro Independiente, todas impulsadas por el Ministerio de Cultura de La 
Nación. Además, el Ingreso Familiar de Emergencia alcanza a varios trabajadrxs del sector y también se otorga ayuda económica desde otros organismos como el Instituto Nacional de la Música, el Instituto Nacional del Teatro y el Fondo Nacional de las Artes.

El Estado provincial otorgó algunos beneficios a nivel impositivo y facilitó la realización de ciertos trámites. Además, los espacios culturales se vieron directamente beneficiados por el congelamiento de las tarifas de servicios y la suspensión de los cortes por falta de pago. Desde el Ministerio de Cultura de la Provincia de Buenos Aires también se impulsó la convocatoria para artistas llamada Mi Vida en Cuarentena.

En el territorio de La Plata, sin embargo, las cosas son diferentes. Hubo una ausencia total del Estado municipal con respecto a Ixs trabajadorxs de la cultura en todo este período de aislamiento. El gobierno no tuvo ninguna propuesta para el sector en el marco de la pandemia y además, desde el 2019 adeuda pagos de subsidios, de cachet por actuaciones en eventos municipales y de concursos artísticos ganados. El municipio mantiene su postura de total indiferencia y desconocimiento del rol que cumplen las industrias culturales en la comunidad platense, aún en situaciones de emergencia en las que necesitamos la presencia estatal.

\section{Lo organizacional}

El fortalecimiento de las redes de contención, producción, formación y difusión conforman el último de los ejes que sintetizan el debate actual de Ixs actorxs culturales de la región. La capacidad de organización y la opción por el trabajo colectivo son valores constitutivos de las organizaciones de la cultura alternativa en nuestra ciudad. Desde que comenzó el aislamiento se activaron las redes existentes y se conformaron nuevas organizaciones para superar la crisis. A través de grupos de whatsapp y realizando reuniones por videoconferencia, se lograron generar medidas de acción virtuales, nuevas agrupaciones, foros de debate y espacios de circulación de información, difusión y contención para afrontar este momento. Colectivizar las acciones permitió que éstas tomen un impulso y una difusión masiva, haciendo visible una problemática regional que de otra forma hubiese pasado desapercibida entre tantas iniciativas individuales. Esto permitió caracterizar la etapa que estamos viviendo con mayor precisión, relevar un estado de situación de los diferentes proyectos e impulsar acciones que amplíen la llegada de las propuestas y fortalezcan los reclamos. 
Uno de los principales desafíos que se nos presentan ante esta situación es generar un amplio marco de unidad entre las organizaciones conformadas por Ixs distintxs actorxs de la cultura local para lograr articular demandas y medidas de acción. Resulta necesario fortalecer las organizaciones para enfrentar los meses que vienen y abordar en conjunto la pospandemia de manera inteligente. Las redes tejidas en este contexto serán la herramienta necesaria para construir los cimientos de lo nuevo que está por venir. Esta crisis nos deja en una situación compleja en el plano económico, pero su potencia transformadora nos abre un horizonte de lucha contra los modelos hegemónicos de cultura que debemos afrontar con unidad y organización.

Tenemos la oportunidad de debatir el futuro. Hay una conciencia global de que el mundo se está transformando. Uno de los escenarios probables a mediano plazo es la transición hacia un nuevo modelo de acumulación capitalista. La construcción en red será una forma de incidir en las tramas que irán provocando esa transformación, para lograr torcerla hacia el mundo que buscamos construir. Por eso resulta necesario hoy, más que nunca, que entre todxs logremos que subsistan estas nuevas formas de crear que venimos construyendo hace años desde la cultura alternativa en nuestra ciudad.

La Plata, 30 de abril de 2020 